\title{
Qualitative Determination, Quantitative Evaluation and Comparative Insecticidal Potential of Ruta Graveolens Essential Oil and Its Major Constituents in the Management of Two Stored Pests Sitophilus Zeamais (Coleoptera: Curculionidae) And Corcyra Cephalonica (Lepidoptera: Pyralidae)
}

\author{
A.G.W.U. Perera ${ }^{1}$, M.M.S.C. Karunaratne ${ }^{1} \&$ S.D.M. Chinthaka ${ }^{2}$ \\ ${ }^{1}$ Department of Zoology, Faculty of Applied Sciences, University of Sri Jayewardenepura, Nugegoda, Sri Lanka \\ ${ }^{2}$ Department of Chemistry, Faculty of Applied Sciences, University of Sri Jayewardenepura, Nugegoda, Sri Lanka \\ Correspondence: A.G.W.U. Perera, Department of Zoology, Faculty of Applied Sciences, University of Sri \\ Jayewardenepura, Nugegoda, Sri Lanka. E-mail: wathsala@sci.sjp.ac.lk
}

Received: December 1, 2019 Accepted: December 15, 2019 Online Published: December 30, 2019

\begin{abstract}
Eco-chemical control based on essential oil mediated plant-insect interactions is an alternative method to the unsystematic use of insecticides, due to advanced structural diversity and allelopathic potential of essential oils. In this sense, present work was aimed at qualitative and quantitative investigation of chemical composition and the evaluation of insecticidal activities of Ruta graveolens essential oil and its major constituents against Sitophilus zeamais and Corcyra cephalonica in stored maize. Fresh leaves were subjected to hydrodistillaton and the chemical composition of oil was studied. Essential oil and its major constituents were then assessed for their allelopathic activity on test insects. Fifty components were identified, where long chain aliphatic 2-methyl ketones predominated the oil as major constituents. Results revealed strong concentration-, insect species- and timedependent toxicities, in which oil caused $100 \%$ mortalities at concentrations of 1.52 and $0.46 \mu \mathrm{L} / \mathrm{cm}^{2}$ against $S$. zeamais and C. cephalonica respectively after 24 hours of exposure. In aliphatic 2-methyl ketone series, respective congeners having odd and even number of carbon atoms were more effective on S. zeamais and C. cephalonica. These findings provide a scientific basis for the eco-potential of using essential oil of $R$. graveolens and its major constituents in integrated insect pest management programs.
\end{abstract}

Keywords: Ruta graveolens, Sitophilus zeamais, Corcyra cephalonica, contact insecticidal activity, long chain aliphatic methyl ketones

\section{Introduction}

Synthetic insecticides are being extensively used with the view of protecting stored grains in increasing yields which also have triggered many undesirable impacts on entire ecosystems, society and every aspect of life on earth. Thus, the development of green insecticides has been focused as a viable pest management strategy in IPM programs in recent years (Khani and Rahdari, 2012). Particularly, plant essential oils and their constituents have been extensively studied and proposed as being a high potential option (Pumnuan et al., 2015; Guo et al., 2015) due to their specificity in exerting wide array of known biological influences on insects including repellent, deterrent or antifeedant, inhibition of digestion, increasing oviposition or contrarily decreasing reproduction by ovicidal and larvicidal effects (Regnault-Roger, 1997). The high volatility of plant essential oils and their constituents reduce the concern for their residues on stored grains (Kim et al., 2016). Different content ratios among the authentic compounds of essential oils will strongly influence its quality which varies with geographical and seasonal variation (Porel et al., 2014). Even the minor compounds should not be disregarded as they contribute significantly to the quality of oil. Hence the accurate quantification of individual compounds of essential oils is a key element in research or industrial analysis which may be used to understand the relationship not only between the constituent structure and aroma of essential oils (Zhu et al., 2005), but also between the constituent structures and their broad spectrum of biological properties against insect pests.

During our screening process oriented in search of bioactive constituents to replace the use of synthetic insecticides, the essential oil of Ruta graveolens was found to possess contact insecticidal activity against the maize weevil, 
Sitophilus zeamais Motschulsky, and the rice moth, Corcyra cephalonica Stainton. which are two key pests of cereal grains in tropical and subtropical regions of the world (Krishna-Ayyar, 1930). Even though Jayaweera (1982) reported the major constituents of $R$. graveolens essential oil as 2-nonanone and 2-undecanone, the entire profile on the chemical composition of the oil of $R$. graveolens, growing in Sri Lanka, has never been established. While, the number of reports the insecticidal properties of essential oil of $R$. graveolens (Jeon et al., 2015) is very limited, literature survey has shown that there is neither a report on quantitative evaluation of the major essential oil constituents nor on their comparative insecticidal activities.

In this phytocentric study, we performed qualitative and quantitative determination of Ruta graveolens essential oil and its constituents. Using the results thus obtained, we comparatively evaluated the contact insecticidal effect of the essential oil together with its constituents with the view of identifying and characterizing bio-active constituents of the essential oil to be utilized in the management of S. zeamais and C. cephalonica under laboratory conditions.

\section{Materials and Methods}

\subsection{Test Insects}

Maize weevils (Sitophilus zeamais) and rice moths (Corcyra cephalonica) were obtained from the cultures reared on respective media of whole, un-infested maize grains and coarsely ground maize in the Agricultural Insect Pest Management Laboratory of Department of Zoology, Faculty of Applied Sciences, University of Sri Jayewardenepura, Sri Lanka. The relative humidity, light regime and ambient temperature during the experimental period were $84 \pm 2 \% \mathrm{RH}, 12 \mathrm{~h}: 12 \mathrm{~h}$ light:dark, and $29 \pm 2^{\circ} \mathrm{C}$ respectively. One week old, unsexed adult weevils and $<24 \mathrm{~h}$ old rice moths were used in all bioassays.

\subsection{Plant Material}

Fresh, mature and healthy leaves of Ruta graveolens were collected from a local market at Colombo Fort, Sri Lanka. These were coarsely powdered by using a domestic electric grinder (Multinational ${ }^{\mathbb{}}, 2101$, India).

\subsection{Essential Oil Extraction}

The essential oil was extracted by hydro-distillation of the ground plant leaves $(250 \mathrm{~g}$ of sample in $2.5 \mathrm{~L}$ of distilled water) using a modified Clevenger-type apparatus for $5 \mathrm{~h}$ with 3 replications. The superior phase was collected from the condenser, dried over anhydrous sodium sulphate and stored in sealed glass vials at $4^{0} \mathrm{C}$ prior to analysis. The essential oil extraction was carried out in the laboratory at the Ayurvedic Research Institute, Navinna, Maharagama, Sri Lanka.

\subsection{Reference Compounds and Reagents}

Pure commercial standard compounds of 2-octanone (C8), 2-nonanone (C9), 2-decanone (C10), 2-undecanone (C11), 2-dodecanone (C12), 2-tridecanone (C13) representing the 2-ketone series were purchased from SigmaAldrich (USA). These reference compounds were selected due to their top-tier presence in the essential oil composition of $R$. graveolens. Acetone (analytical grade quality) for Gas Chromatography-Mass Spectrometry (GC-MS) Analysis was also purchased from Sigma-Aldrich, USA. The other standard compounds were all in GC purities.

\subsection{Sample Preparation}

For the characterization of essential oil composition of $R$. graveolens through GC-MS analysis, $12 \mu \mathrm{L}$ of accurately measured essential oil sample was dissolved in $1 \mathrm{~mL}$ of Acetone. Then $2 \mu \mathrm{L}$ of the solution was injected into the GC-MS system.

For GC-MS analysis, a standard cocktail comprising long chain aliphatic methyl ketone constituents was prepared separately, in order to detect and quantify the compounds of interest. The cocktail which is a mixed stock solution containing reference standards $(\mathrm{C} 8, \mathrm{C} 9, \mathrm{C} 10, \mathrm{C} 11, \mathrm{C} 12$, and $\mathrm{C} 13)$ was prepared by dissolving $12 \mu \mathrm{L}$ of accurately measured standard of each compound in acetone targeting a stock concentration of $100 \mu \mathrm{gmL}^{-1}$ for the cocktail. Dilutions of the standard cocktail were made in acetone to produce concentrations of the compounds ranged at 10$50 \mu \mathrm{gmL}^{-1}$.

\subsection{Gas Chromatography-Mass Spectrometry (GC-MS) Analysis}

Chemical standards and EO of $R$. graveolens were analyzed using an Agilent Technologies 7890A GC system (Palo Alto, CA) equipped with an Agilent Technologies 5975C inert XL EI/CI mass spectrometer. A DB-5MS fused silica capillary column of $30 \mathrm{~m} \times 0.25 \mathrm{~mm}$ (J \& W Scientific, Folsom, CA) was used. The temperature was programmed as follows: initial oven temperature was $700 \mathrm{C}$, held for 2 minutes, and then ramped at $100 \mathrm{C} / \mathrm{min}$ up 
to $2800 \mathrm{C}$, where it was held for 7 minutes. The injector and detector temperatures were set at $2750 \mathrm{C}$ using helium as the carrier gas, at a flow rate of $1 \mathrm{~mL} / \mathrm{min}$. The injection volume of the sample was $2 \mu \mathrm{L}$ using the split flow mode (split ratio, 5:1).

The identification of EO components was based on the NIST reference mass spectral library provided with the GC-MS equipment. The composition was reported as a relative percentage of the total peak area. EO constituents were ranged into 2 molecular framework categories of aliphatic and aromatic compounds.

\subsection{Quantification of Key Essential Oil Constituents}

Based on the prolific percentage in the functional group composition (56.16\%) of essential oil, long chain aliphatic methyl ketones were selected for their quantitative determination of the essential oil of $R$. graveolens. Calibration graphs were constructed using the series of standard solutions of varying nominal concentrations containing known amounts of 2-methyl ketone constituents prepared with acetone. Concentration and absolute percentage of each chemical constituent in $R$. graveolens $\mathrm{EO}$ were evaluated by comparison of the chromatographic peak areas of reference compounds in standard solutions with those of authentic compounds present in the EO extract of $R$. graveolens.

\subsection{Insecticidal Effect by Contact With Treated Glass}

Preliminary range finding studies were conducted in order to determine the appropriate testing concentrations of the EO of $R$. graveolens to be applied against $S$. zeamais and $C$. cephalonica. A series of concentrations for the EO and its major long chain aliphatic 2- methyl ketone constituents were prepared in acetone, where each concentration of individual compounds was prepared according to their persisting authentic proportions in the EO composition of $R$. graveolens.

The contact insecticidal effect of the EO and individual compounds against $S$. zeamais adults was measured as described by Kouninki et al. (2007) and Betancur et al. (2010) with slight modifications. Aliquots of $0.5 \mathrm{~mL}$ of the prepared concentrations of EO $(0.047,0.095,0.190,0.304,0.456,0.760,1.520,3.040,6.079$, and 12.158 $\mu \mathrm{L} / \mathrm{cm}^{2}$ ) and respective corresponding concentrations of each 2-methyl ketone constituent were applied evenly on the inner surface of glass tubes (diameter $1 \mathrm{~cm}$, height $10 \mathrm{~cm}$, volume $10 \mathrm{~mL}$ ) and the screw caps. The tubes were agitated for the oil and constituents to uniformly cover the interior surface and then the acetone was allowed to evaporate at ambient temperature for 2 hours. After evaporation of solvents completely, 20 adult maize weevils were introduced into each tube and was then covered with muslin cloth held in place with rubber bands to allow ventilation of weevils. Insect mortality was assessed at 6,12 and $24 \mathrm{~h}$ of exposure to the solutions. Glass tubes treated with acetone alone were used as the control. Each concentration and the control were replicated 5 times.

The contact toxic potential of the $R$. graveolens $\mathrm{EO}$ and its individual components against $C$. cephalonica adult moths was investigated using the same bioassay setup of $S$. zeamais with some alterations. After the application of different concentrations of $\mathrm{EO}\left(0.007,0.014,0.029,0.046,0.070,0.116,0.232,0.464,0.928\right.$, and $\left.1.856 \mu \mathrm{L} / \mathrm{cm}^{2}\right)$ and respective corresponding concentrations of each 2-methyl ketone constituent, which followed by agitation and evaporation of acetone, 10 adult moths were transferred to both treated and control glass tubes (diameter $4 \mathrm{~cm}$, height $15 \mathrm{~cm}$ ). Insect mortality was checked after 6,12 and $24 \mathrm{~h}$ of the moth exposure. Five replicates were made in all treatments and control where acetone was used as the control.

\subsection{Statistical Analysis}

Mortality was corrected according to Abbott's formula (Abbott, 1925) and all data were subjected to one-way analysis of variance (ANOVA) using the Minitab software, version 14.0. Tukey's multiple comparison test was used to separate mean values of the experiments, where significant differences existed $(\mathrm{p}<0.05)$. Probit analysis was used to estimate $\mathrm{LC}_{50}$ values to determine the lethal concentrations needed to kill $50 \%$ of $S$. zeamais and $C$. cephalonica.

\section{Results and Discussion}

\subsection{Identification of Chemical Composition of R. graveolens Essential Oil}

The $R$. graveolens essential oil obtained was light yellow in color with a yield of $0.2 \% \mathrm{v} / \mathrm{w}$. The oil exhibited a more diverse chemical composition where a total of 50 components were identified accounting for $87.59 \%$ of the total oil (Table 1). According to the fingerprint chemical profile of essential oil, it is noticeable that the main constituents were 2-undecanone (30.671\%) and 2-nonanone (20.790\%) while long chain aliphatic 2-methyl ketones profusely maintaining the predominance oil composition. 
Table 1. Percentage chemical composition of Ruta graveolens essential oils produced in Sri Lanka

\begin{tabular}{|c|c|c|c|}
\hline $\begin{array}{l}\text { Molecular } \\
\text { Framework }\end{array}$ & Volatile Organic Compound ${ }^{\mathrm{a}}$ & $\mathbf{R}^{\mathbf{b}}$ & $\begin{array}{c}\text { Percentage } \\
(\%) *\end{array}$ \\
\hline \multirow[t]{30}{*}{ Aliphatic } & Organooxygen Compounds & & 2.18 \\
\hline & Diacetone alcohol & 2.72 & 1.64 \\
\hline & Nonanal & 6.45 & 0.37 \\
\hline & Decanal & 7.97 & 0.17 \\
\hline & Long chain aliphatic methyl ketones & & 56.16 \\
\hline & 2-Octanone & 4.66 & 0.49 \\
\hline & 2-Nonanone & 6.34 & 20.79 \\
\hline & 2-Decanone & 7.78 & 2.71 \\
\hline & 2-Undecanone & 9.39 & 30.67 \\
\hline & 2-Dodecanone & 10.64 & 1.19 \\
\hline & 2-Tridecanone & 11.94 & 0.31 \\
\hline & Fatty Acyls & & 0.61 \\
\hline & Nonyldichloroacetate & 7.45 & 0.46 \\
\hline & 2-Acetoxytetradecane & 11.09 & 0.14 \\
\hline & Fatty alcohols & & 0.08 \\
\hline & 1-Nonanol & 9.49 & 0.05 \\
\hline & Behenyl alcohol & 21.73 & 0.03 \\
\hline & Sesquiterpenoids & & 1.44 \\
\hline & .alpha-Farnesene & 12.10 & 0.31 \\
\hline & Elemol & 12.70 & 0.05 \\
\hline & $\gamma$-Eudesmole & 13.72 & 0.19 \\
\hline & $\alpha$-Eudesmol & 13.99 & 0.99 \\
\hline & Diterpenoids & & 0.12 \\
\hline & Phytol & 18.54 & 0.12 \\
\hline & Acyclic alkanes & & 0.33 \\
\hline & Octadecane & 23.29 & 0.33 \\
\hline & Saturated hydrocarbons & & 0.19 \\
\hline & Hexadecane & 13.16 & 0.19 \\
\hline & Lineolic acids and derivatives & & 0.02 \\
\hline & Linoleic acid & 16.45 & 0.02 \\
\hline \multirow[t]{13}{*}{ Aromatic } & Phenol ethers & & 2.91 \\
\hline & 1-Methoxy-2-methylbenzene & 4.99 & 0.17 \\
\hline & 1-Methoxy-4-methylbenzene & 5.16 & 0.11 \\
\hline & 2,3-Dimethylanisole & 6.54 & 0.25 \\
\hline & 3,5-Dimethylanisole & 6.71 & 0.06 \\
\hline & 5,6-Diethenyl-1-methyl cyclohexene & 7.08 & 2.32 \\
\hline & Monoterpene & & 0.11 \\
\hline & D-Limonene & 5.28 & 0.11 \\
\hline & Arene & & 0.92 \\
\hline & Indene & 5.57 & 0.05 \\
\hline & Biphenylene & 11.49 & 0.23 \\
\hline & 1H-Phenalene & 12.94 & 0.64 \\
\hline & Benzene and substituted derivatives & & 0.59 \\
\hline
\end{tabular}




\begin{tabular}{lcc} 
2,3-Dimethoxytoluene & 8.49 & 0.29 \\
Biphenyl & 10.54 & 0.20 \\
Benzenebutanol & 14.11 & 0.11 \\
\hline Pyridines and derivatives & & $\mathbf{6 . 7 3}$ \\
4-Hydoroxypyridine1-oxide & 9.62 & 6.73 \\
\hline Methoxybenzenes & & $\mathbf{0 . 7 8}$ \\
4-Ethyl-1,2-dimethoxybenzene & 9.70 & 0.45 \\
Methyleugenol & 10.79 & 0.33 \\
\hline Naphthalenes & & $\mathbf{2 . 2 2}$ \\
2-Ethenyl naphthalene & 11.22 & 0.87 \\
\hline 2-Phenyl naphthalene & 17.40 & 0.15 \\
Fluoranthene & 18.30 & 1.20 \\
\hline Phenols and derivatives & & $\mathbf{1 . 5 7}$ \\
Acetosyringone & 11.76 & 1.57 \\
\hline Benzodioxoles & & $\mathbf{0 . 3 2}$ \\
\hline 4-(3,4-Methylenedioxyphenyl)-2-butanone & 13.29 & 0.27 \\
5-(2,2-dimethylethyl) 1,3-benzodioxole & 15.66 & 0.05 \\
\hline Phenanthrenes & & $\mathbf{6 . 3 0}$ \\
Phenanthrene & 14.50 & 0.77 \\
1-Methylphenanthrene & 16.64 & 0.11 \\
4H-Cyclopenta[def]phenanthrene & 16.88 & 0.05 \\
\hline Pyrene & 18.81 & 5.37 \\
\hline Anthracenes & & $\mathbf{3 . 0 7}$ \\
Anthracene & 15.43 & 3.07 \\
\hline Other & & $\mathbf{0 . 9 5}$ \\
1-Ethyl-4-methoxybenzene & 6.63 & 0.07 \\
Dibenzofuran & 12.34 & 0.83 \\
n-Heptanoicacid,methyl(tetramethylene)silyl ester & 19.30 & 0.05 \\
\hline Total & & $\mathbf{8 7 . 5 9}$ \\
\hline Prmally on & & \\
\hline
\end{tabular}

${ }^{a}$ Compounds listed primarily on the basis of class category percentage and secondarily on the individual percentage within the respective category, $\mathrm{R}_{\mathrm{t}}{ }^{\mathrm{b}}-$ Retention time of the essential oil solution, * Data are expressed as percentage of the total peak area.

The results of the analysis of the present study were to some extent in agreement with the other literature that reported 2-undecanone and 2-nonanone as major constituents in the essential oil of $R$. graveolens grown in Egypt, Hong Kong, Tunisia and Iran (Aboutab et al., 1988; Zhu et al., 1993; Fredj et al., 2007; Soleimani et al., 2009) with a slight exception where in Jordan the major compounds of $R$. graveolens essential oil were reported to be 2nonanone and undecanal (Al-Shuneigat et al., 2015). However, there were overall differences in each oil compositions with respect to the relative proportions of each compound and the presence or absence of the other minor components. These variations may be attributed to plant part, season, method of harvesting, geographical zone, and isolation method of plant product (Khani and Rahdari, 2012).

However, several identified essential oil constituents could be formed by autoxidation during the sample preparation procedures. Moreover, there are some limitations for volatile compounds as structural alterations of thermally labile compounds may occur during analysis due to high temperature of injector or columns in GC method (Porel et al., 2014). According to Adam (1995), essential oils are comprised of vast number of compounds and like materials, thus, similarity of retention indices of many related compounds will result in overlapping peaks in chromatograms. The presence of unsaturated bonds, various branched and cyclic compounds, and oxygenated analogues including alcohols and ketones would further complicate this issue (Zhu et al., 2005). 


\subsection{Quantitative Determination of Key Long Chain Aliphatic 2-methyl Ketone Constituents of R. Graveolens Essential oil}

Experimentations on the structure-activity relationship of some essential oil constituents, have revealed that the oil constituents with ketone functional groups are usually stronger in their insecticidal potential, than those of hydrocarbons (Kim et al., 2016), thus emphasizing the fact that assessing the bioactivity of chemical constituents belonging to such functional groups to be of high priority. Accordingly, based on both prolific percentages in the functional group composition (56.16 \%), long chain aliphatic methyl ketones were selected for their quantitative determination of the essential oil of $R$. graveolens. Calibration curves were thus constructed for the major congeners of 2-methyl ketone series (C8-C13) which followed linear relationships. The detailed results of the regression equations, corresponding correlation coefficients and original percentage of each compound in $R$. graveolens essential oil are shown in Table 2.

Table 2. Regression equations, correlation coefficients and original percentages of key long chain aliphatic 2methyl ketone constituents identified in the Ruta graveolens essential oils

\begin{tabular}{ccccc}
\hline Compounds & $\begin{array}{c}\text { Molecular } \\
\text { Formula }\end{array}$ & Regression Equation & $\mathbf{r}^{\mathbf{2}}$ & $\begin{array}{c}\text { Original } \\
\text { Percentage in } \\
\text { Essential oil } \\
\mathbf{( \% )}\end{array}$ \\
\hline 2-Octanone & $\mathrm{C}_{8} \mathrm{H}_{16} \mathrm{O}$ & $\mathrm{y}=444,504.67 \mathrm{x}+3,033,841.15$ & 0.9654 & 0.447 \\
\hline 2-Nonanone & $\mathrm{C}_{9} \mathrm{H}_{18} \mathrm{O}$ & $\mathrm{y}=431,260.77 \mathrm{x}+95,125.927$ & 0.9882 & 22.684 \\
\hline 2-Decanone & $\mathrm{C}_{10} \mathrm{H}_{20} \mathrm{O}$ & $\mathrm{y}=576,824.01 \mathrm{x}-1,312,092.54$ & 0.9838 & 2.230 \\
\hline 2-Undecanone & $\mathrm{C}_{11} \mathrm{H}_{22} \mathrm{O}$ & $\mathrm{y}=802,213.27 \mathrm{x}-4,180,855.08$ & 0.9724 & 17.760 \\
\hline 2-Dodecanone & $\mathrm{C}_{12} \mathrm{H}_{24} \mathrm{O}$ & $\mathrm{y}=745,619.20 \mathrm{x}+1,962,139.23$ & 0.9870 & 0.727 \\
\hline 2-Tridecanone & $\mathrm{C}_{13} \mathrm{H}_{26} \mathrm{O}$ & $\mathrm{y}=826,175.07 \mathrm{x}+8,085,014.92$ & 0.9628 & 0.786 \\
\hline & & Total & & $\mathbf{4 4 . 6 4 3}$ \\
\hline
\end{tabular}

In the regression equation $\mathrm{y}=\mathrm{mx}+\mathrm{c}, \mathrm{x}$ refers to the sample injection amount, $\mathrm{y}$ to the peak area, $\mathrm{r}^{2}-$ Correlation coefficient of the equation

Quantitative analysis produced better and confirmatory proof for long chain aliphatic methyl being the foremost functional group in the $R$. graveolens essential oil as evidenced in the qualitative determination. These ketones solely established $44.643 \%$ of the total oil content with 2-undecanone and 2-nonanone being occupying over $40 \%$ of the total content.

\subsection{Insecticidal effect on $S$. zeamais and C. cephalonica by contact with treated glass}

The contact insecticidal effects of $R$. graveolens essential oil and its principle long chain 2-methyl ketone constituents applied onto a glass surface against S. zeamais are shown in Figure 1. In all instances, considerable differences in insecticidal activity of essential oil and its ketone constituents on insects were observed with the increase in concentrations and time periods after application. Results indicated that the oil itself produced relatively the highest insecticidal effects than any of its ketone constituents at each concentration level during each time period. The oil produced $100 \%$ mortality of $S$. zeamais after $24 \mathrm{~h}$ exposure at an intermediate concentration of $1.52 \mu \mathrm{L} / \mathrm{cm}^{2}$. The most abundant constituents of 2-nonanone and 2-undecanone exhibited significantly similar protection efficacy over $S$. zeamais at each concentration, exerting $100 \%$ weevil mortalities at the corresponding concentrations of 1.38 and $2.15 \mu \mathrm{L} / \mathrm{cm}^{2}$ after $24 \mathrm{~h}$ of post treatment. 2-Tridecanone showed only moderate insecticidal potential with all corresponding test concentrations at each time interval, while 2-octanone followed by 2 - dodecanone produced the least insecticidal effect only after 24 hours of weevil introduction. On the contrary, 2-decanone was not effective against $S$. zeamais notwithstanding the concentrations and exposure periods. 


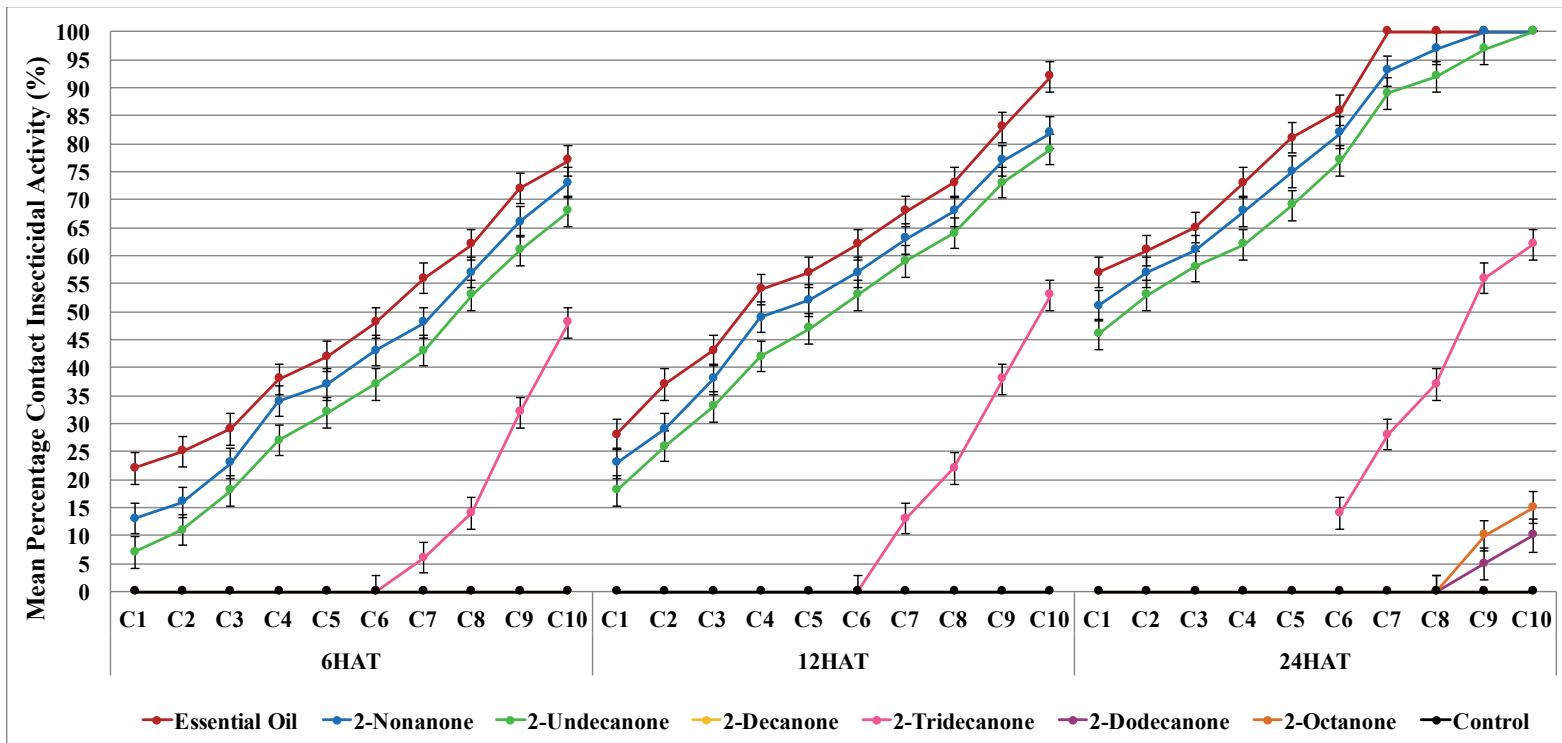

Figure 1 Mean percentage contact insecticidal activity $( \pm \mathrm{SD})$ of R. graveolens essential oil and its principle long chain aliphatic 2-methyl ketone constituents against $\mathrm{S}$. zeamais at 6,12 and 24 hours of weevil exposure to treated glass. $\mathrm{C}=$ Concentration based on 10 levels of essential oil content $(0.047,0.095,0.189,0.303,0.455$, $0.758,1.517,3.033,6.066,12.132 \mu \mathrm{L} / \mathrm{cm} 2) ; \mathrm{HAT}=$ Hours After Treatment; $\mathrm{n}=100$

Results in terms of contact insecticidal effectiveness of $R$. graveolens essential oil and its principle long chain 2methyl ketone constituents applied on a glass surface at different concentrations against adult $C$. cephalonica are illustrated in Figure 2. Cumulative insect mortalities increased with the increase of concentrations and exposure time. Essential oil was found to be greatly effective on rice moths, achieving $100 \%$ adult mortalities after an exposure period of only 12 hours at the highest concentration of $1.86 \mu \mathrm{L} / \mathrm{cm}^{2}$. The insecticidal activity of 2undecanone followed by 2-nonanone, were comparable to that of essential oil at all concentrations. 2-Undecanone and 2-nonanone revealed $100 \%$ C. cephalonica mortalities at the corresponding concentrations of 0.16 and 0.45 $\mu \mathrm{L} / \mathrm{cm}^{2}$ after $24 \mathrm{~h}$ of exposure respectively. 2-Decanone produced strong maize protection efficacy accounting for $88 \%$ while, 2-dodecanone and 2-tridecanone inducing moderate potency against $C$. cephalonica at the corresponding concentrations of the highest essential oil concentration at $24 \mathrm{~h}$ of post treatment. The 2- octanone exerted the weakest insecticidal action on rice moths only after 24 hours compared to the other compounds in aliphatic methyl ketone series. 


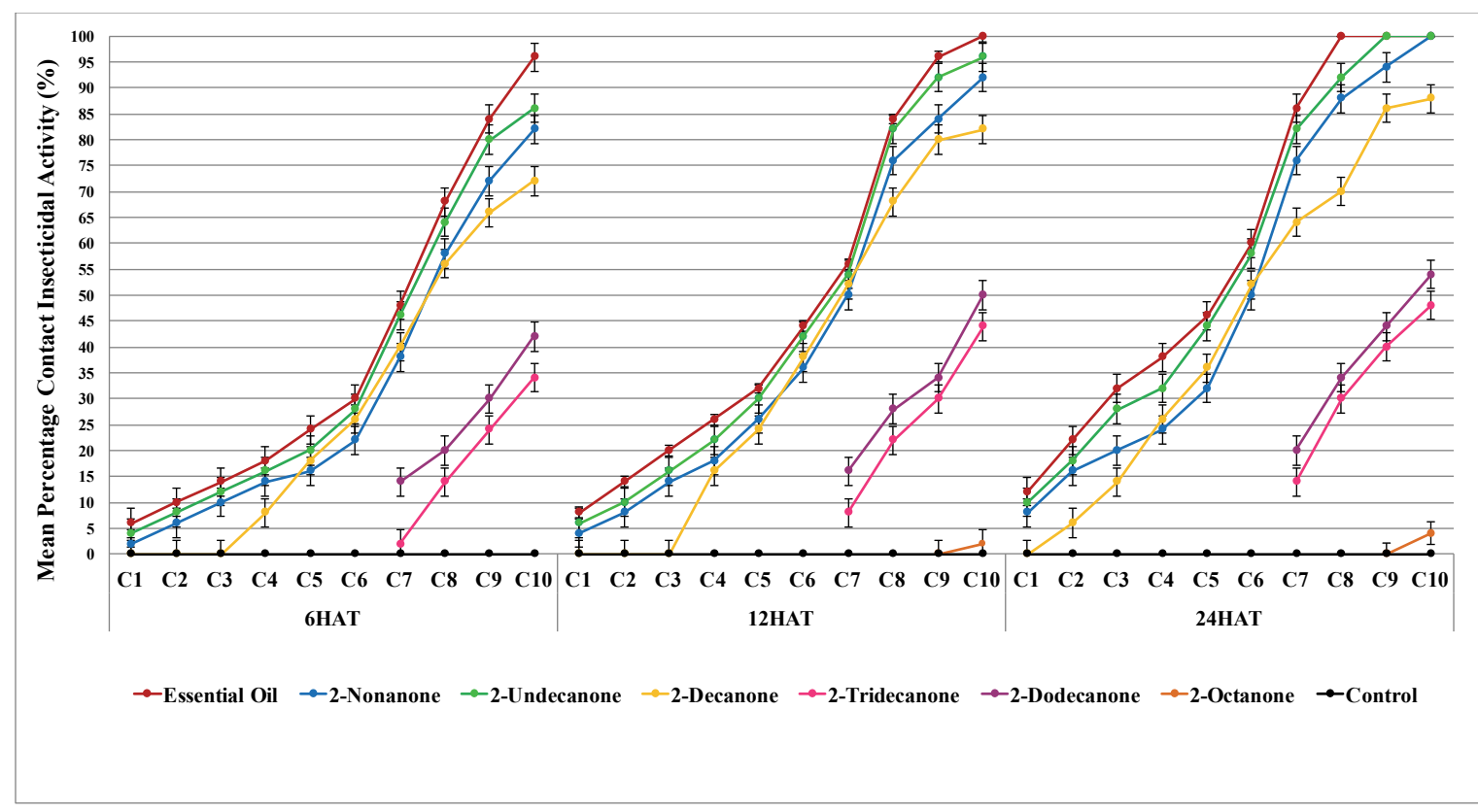

Figure 2 Mean percentage contact insecticidal activity $( \pm \mathrm{SD})$ of $R$. graveolens essential oil and its principle long chain aliphatic 2-methyl ketone constituents against $C$. cephalonica at 6,12 and 24 hours of weevil exposure to treated glass. $\mathrm{C}=$ Concentration based on 10 levels of essential oil content $(0.007,0.014,0.029,0.046,0.070$,

$\left.0.116,0.232,0.464,0.928,1.856 \mu \mathrm{L} / \mathrm{cm}^{2}\right) ; \mathrm{HAT}=$ Hours After Treatment; $\mathrm{n}=50$

Results of the probit regression analysis shown in Table 3 revealed that $S$. zeamais is more tolerant to $R$. graveolens essential oil and its 2-ketone analogues than C. cephalonica. Regarding $\mathrm{LC}_{50}$ values of 2-methyl ketone series, it was observed that the odd-chained congeners were more effective than those of the even-chained congeners on $S$. zeamais with the exception of 2-decanone being not effective against $S$. zeamais within the corresponding measure range to essential oil concentrations, hence its $\mathrm{LC}_{50}$ value could not be calculated $\left(\mathrm{LC}_{50}>0.095\right.$ mortality $0 \%$ ). In respect to $C$. cephalonica, an inverse pattern could be observed, of which the insecticidal potency of even-chained congeners over the odd-chained congeners was apparent.

Table 3. $\mathrm{LC}_{50}$ values of $R$. graveolens essential oil and its major constituents against the adults of S. zeamais and C. cephalonica

\begin{tabular}{|c|c|c|c|c|c|}
\hline \multirow{2}{*}{ Insect } & \multirow{2}{*}{ Treatments" $^{*}$} & \multirow{2}{*}{$\mathbf{L C}_{50} \mathbf{a}, \mathbf{b}$} & \multicolumn{2}{|c|}{$\begin{array}{c}\text { Confidence } \\
\text { Interval }^{\mathbf{b}}\end{array}$} & \multirow{2}{*}{ Slope $\pm \mathbf{S E}$} \\
\hline & & & Lower & Upper & \\
\hline \multirow{7}{*}{ S. zeamais } & Essential oil & 0.059 & 0.041 & 0.468 & $0.51 \pm 0.04$ \\
\hline & 2-Octanone & 0.145 & 0.091 & 94.370 & $0.94 \pm 0.21$ \\
\hline & 2-Nonanone & 0.017 & 0.012 & 0.098 & $0.46 \pm 0.04$ \\
\hline & 2-Decanone & $>0.095$ (Mortality $0 \%)$ & - & - & - \\
\hline & 2-Undecanone & 0.017 & 0.012 & 0.126 & $0.42 \pm 0.03$ \\
\hline & 2-Dodecanone & 0.325 & 0.172 & 343.732 & $0.93 \pm 0.27$ \\
\hline & 2-Tridecanone & 0.044 & 0.034 & 6.635 & $0.50 \pm 0.06$ \\
\hline \multirow{7}{*}{$\begin{array}{c}C . \\
\text { cephalonica }\end{array}$} & Essential oil & 0.055 & 0.187 & 0.245 & $0.72 \pm 0.04$ \\
\hline & 2-Octanone & 0.011 & - & -1 & $\begin{array}{c}- \\
\end{array}$ \\
\hline & 2-Nonanone & 0.022 & 0.019 & 0.026 & $0.68 \pm 0.04$ \\
\hline & 2-Decanone & 0.006 & 0.005 & 0.007 & $0.60 \pm 0.03$ \\
\hline & 2-Undecanone & 0.022 & 0.019 & 0.026 & $0.70 \pm 0.04$ \\
\hline & 2-Dodecanone & 0.009 & 0.007 & 0.017 & $0.45 \pm 0.09$ \\
\hline & 2-Tridecanone & 0.016 & 0.013 & 0.023 & $0.89 \pm 0.11$ \\
\hline
\end{tabular}

${ }^{\mathrm{a}}$ Units $\mathrm{LC}_{50}=\mu \mathrm{l} / \mathrm{cm}^{2}$ applied for $24 \mathrm{~h}$ time period; ${ }^{\mathrm{b}} 95 \%$ lower and upper confidence limits are shown in parenthesis; ${ }^{*}$ Mortality of the control (acetone) was $0 \mu \mathrm{l} / \mathrm{cm}^{2}$ for both $S$. zeamais and C. cephalonica 
Jeon et al (2015) outlined the insecticidal capacity of $R$. graveolens essential oil and its commercial phenolic analogs against Sitophilus zeamais, Sitophilus oryzae and Lasioderma serricorne. Ali et al (2013) gave a detailed account on the larvicidal potential of 2-nonanone followed by 2-undecanone against Anopheles quadrimaculatus and Aedes aegypti. 2-Undecanone was found capable of causing larval mortality in Heliothis zea (Robert et al., 1987). Meanwhile, it has been reported that normal odd-chained alkanones of 2-undecanone and 2-tridecanone are acutely toxic to neonate larvae of Keiferia lycopersicella and Spodoptera exigua (Lin et al., 1987). In addition, 2tridecanone seemed to have a remarkable role in insecticidal resistance to Manduca sexta, Heliothia zea and Leptinotarsa decemlineata (Kennedy and Dimock, 1982). Moreover, 2-dodecanone was also effective against tobacco hornworm, the $M$. sexta with $\mathrm{LC}_{50}$ value of $0.028 \mu \mathrm{m} / \mathrm{cm}^{2}$ (Antonious et al., 2003). 2-Dodecanone and 2tridecanone were about equal in toxicity towards green peach aphid (Myzus persicae) which required a significantly lower dose than 2-undecanone. The spider mite (Tetranychus urticae) was more tolerant to 2undecanone and 2-dodecanone than 2-tridecanone thus delineating that there are differences in sensitivity among arthropods in their sensitivity to constituents of potential bio-pesticides (Antonious et al., 2003; Antonious and Snyder, 2008).

Although the two active major constituents (2-nonanone and 2-undecanone) of tested essential oil influenced comparable and strong protection efficacy, the insecticidal potential of essential oil may be ascribed in part, but not exclusively, to the total content ( $40.44 \%$ of the total oil) of those active major constituents. For the reason that essential oils always represent a complex mixture of many chemical compounds and thus it is rather difficult to reduce the effect of the total oil to a few active components (Guo et al, 2016). Besides, some compounds identified in the $R$. graveolens essential oil also have demonstrated bioactivities against wide array of insect pests. Linoleic acid was found to be toxic against the larval stages of Spodptera llittoralis (Heba et al., 2013) and $4^{\text {th }}$ larvae of Aedes aegypti, Anopheles stephensi and Culex quinquefasciatus (Rahuman and Venkatesan, 2008). It has been reported that d-limonene was toxic to Rhyzopertha dominica, Stiophilus oryzae and Tribolium castaneum (Tripathi et al., 2003). In addition, methyleugenol is known to have strong contact insecticidal properties on S. zeamais with $\mathrm{LD}_{50}$ value being approximately $30 \mu \mathrm{g} / \mathrm{mg}$ insect. Moreover, methyleugenol reported to have negative impact on the RGR (Reduced Growth Rate) and RCR (Reduced Food Consumption) of Sitophilus zeamais and Tribolium castaneum with decreased ECI (Food Consumption and Food Utilization) of S. zeamais adults and T. castaneum larvae (Huang et al., 2002). In that manner, inactive constituents which imposed relatively lower or no insecticidal activity may have some synergistic effect on active constituents, and though not active individually, their presence would be necessary for the essential oil of $R$. graveolens to achieve its comprehensive and complete insecticidal potential. Active constituents, on the other hand, might have an antagonistic effect on each other, since their insecticidal level is significantly greater when tested individually than when they are in an essential oil mixture with other active constituents (Miresmailli et al., 2006). Hence, contact insecticidal property of the essential oils may be related to the synergistic effects of its diverse array of major and minor constituents (Guo et al, 2016).

Due to the observed trend in results, it was evidenced that contact insecticidal activity was the result of differential ability of essential oil and its major authentic constituents in penetrating to more than one active site (Innocent et al., 2008) of the test insects, S. zeamais and C. cephalonica. Thus, having mentioned that, presented results would make a constructive characterization in investigating the relationship between structure and insecticidal activity of congeners in aliphatic 2-methyl ketone series which varying in their chain lengths and carbonyl position. Oddchained and even-chained congeners demonstrated comparable or significantly greater contact insecticidal activities against $S$. zeamais and C. cephalonica respectively. This contingent nature lies in the structure-activity relationship strived against test insects, has been previously explained by Kennedy and Dimock, 1982, assuming that the insecticidal capacity of a congener depends upon the probability of that molecule in reaching the site of action of an insect. In addition, they further clarified that, this probability depends at least in part on the ability of the congener which is determined by the compound's lipophilicity, to pass through lipid barriers such as the cuticle and the cell membranes of the insects. Many studies done for the recognition in the respect of mode of action of natural insecticides have shown that treating insect pests with natural essential oils or their pure compounds may cause symptoms indicating neurotoxic activity that could affect insects through acetyl cholinesterase enzyme inhibition in their central nervous system (Keane and Ryan, 1999), including hyperactivity, seizures and tremors followed by paralysis which are very similar to those produced by the insecticidal pyrethoroids (Kostyukovsky et al., 2002; Khani and Rahdari, 2012). It has also been discovered that the ketone compounds augment the inhibitory effect on acetylcholinesterase due to the presence of the double bond of the carbonyl group (Dambolena et al., 2016). 


\section{Conclusion}

Data of the present study clearly indicated that the essential oil of $R$. graveolens possessed significantly strong insecticidal efficacy, followed by its major functional component of long chain aliphatic 2-methyl ketones constituting C8-C13 congeners against Sitophilus zeamais and Corcyra cephalonica. In that manner these constituents and their parent essential oil of $R$. graveolens leaves play an important role in stored grain protection, thus having the potential for being developed into natural insecticides, reducing the risks associated with the use of conventional chemical control strategies. It might also be useful to create various blends comprising authentic constituents in different rations based on their activity and effect on the insect pests. The current study clearly supports the use of $R$. graveolens essential oil and its long chain aliphatic 2-methyl ketones in the post-harvest control of S. zeamais, C. cephalonica as well as other insect pests of stored maize in the light of recent interest in developing green insecticides in integrated pest management programs. Additionally, for the practical use of essential oil of $R$. graveolens and its major constituents as novel green insecticides, further studies concentrating on their safety to humans are necessary to improve efficacy, potency and stability in the environment.

\section{Abbreviations}

GC-MS: Gas Chromatography-Mass Spectrometry; C8: 2-Octanone; C9: 2-Nonanone; C10: 2-Decanone; C11: 2Undecanone; C12: 2-Dodecanone; C13: 2-Tridecanone

\section{Acknowledgment}

Authors wish to thank R. M. Munasinghe and T. Nawaratne for their technical support.

\section{Funding}

The study was funded by University grants, University of Sri Jayewardenepura, Sri Lanka (Grant no. ASP/01/RE/SCI/2016/35).

\section{References}

Aboutab, E. A., Elazzouny, A. A., \& Hammerschmidt, F. J. (1988). The essential oil of Ruta graveolens L growing in Egypt. Scientia Pharmaceutica, 56, 121-124.

Adams, R. P. (1995). Identification of essential oil components by gas chromatography/mass spectroscopy. Allured Publications, Carol Stream, IL.

Ali, A., Demirci, B., Kiyan, H. T., Bernier, U. R., Tsikolia, M., Wedge, D. E., Khan, I. A., Baser, K. H. C., \& Tabanca, N. (2013). Biting deterrence, repellency, and larvicidal activity of Ruta chalepensis (Sapindales: Rutaceae) essential oil and its major individual constituents against mosquitoes. Journal of Medical Entomology, 50(6), 1267-1274.

Al-Shuneigat, J. M., Al-Tarawneh, I. N., Al-Qudah MA, Al-Sarayreh SA, Al-Saraireh YM and Alsharafa KY (2015). The chemical composition and the antibacterial properties of Ruta graveolens L. essential oil grown in Northern Jordan. Jordan Journal of Biological Sciences, 8(2),139-143.

Antonious, G. F. (2003). Soil infiltration by pesticides. In: Pimentel D (ed) Encyclopedia of pest management, Vol 3. Marcel Dekker, Inc., New York, pp 1-4.

Antonious, GF and Snyder JC (2008). Tomato leaf crude extracts for insects and spider mite control. In: Preedy VR and Watson RR (ed) Tomato and Tomato Products: Nutritiional, Medicinal and Therapeutic Properties. Science Publishers, New Hampshire, pp 269-297.

Betancur, J, Silva G, Rodriquez C, Fisher, S., \& Zapata N (2009). Insecticidal activity of Peumus boldus Molina essential oil against Sitophils zeamais Motschulsky. Chilean Journal of Agricultural Research, 70(3), 399407.

Dambolena, J. S., Zunino, M. P., Herrera, J. M., Pizzolitto, R. P., Areco, V. A., \& Zygadlo, J. A. (2016). Terpenes: Natural products for controlling insects of importance to human health-A structure-activity relationship study. Psyche, 2016, 1-17.

Food and Agricultural Organization of the United Nations (2013). The state of food security in the world. Rome, Italy: FAO Sinha, R. N. (ed). The stored-grain ecosystem. Proceedings of the International Symposium on Stored-Grain Ecosystem. New York, USA: Marcel Dekker, Inc.

Fredj MBH, Marzouk B, Chraief I, Boukef K \& Marzouk Z (2007). Analysis of Tunisian Ruta graveolens L. oils from jemmel. Journal of Food, Agriculture and Environment, 5(1), 52-55.

Guo, S, Zhang, W, Liang, J, You, C., Geng, Z., Wang, C., \& Du, S. (2016). Contact and repellent activities of the 
essential oil from Juniperus formosana against two stored product insects. Molecules, 21(504), 1-11.

Guo SS, You CX, Liang JY, Zhang WJ, Geng ZF, Wang CF, Du SS \& Lei N (2015). Chemical composition and bioactivities of the essential oil from Etlingera yunnanensis against two stored product insects. Molecules, 20, 15735-15747.

Haque MA, Nakakita H, Ikenaga H \& Sota N (2000). Development-inhibiting activity of some tropical plants against Sitophils zeamais Motschulsky (Coleoptera: Curculionidae). Journal of Stored Products Research 36, 281-287.

Heba Y, El-lakwah SF \& El-sayed YA (2013). Insecticidal activity of linoleic acid against Spodoptera lirroralis (Boisd.). Eygyptian Journal of Agricultural Research, 91(2), 573-579.

Huang Y, Ho SH, Lee HC \& Yap YL (2002). Insecticidal properties of eugenol, isoeugenol and methyleugenol and their effects on nutrion of Sitophilus zeamais Motsch. (Coleoptera: Curculionidae) and Tribolium castaneum (Herbst) (Coleoptera: Tenebrinidae). Journal of Stored Products Research, 38(5), 403-412.

Innocent E, Gikonyo NK \& Nkunya MHH (2008). Repellency property of long chain aliphatic methyl ketones against Anopheles gambiae s.s. Tanzania Journal of Health Research, 10(1), 50-54.

Jayaweera, DMA (1982). Medicinal Plants (Indigenous \& Exotic) Used in Ceylon. Colombo, Sri Lanka: The National Science Council of Sri Lanka.

Jeon JH, Lee SG \& Lee HS (2015). Isolation of insecticidal constituent from Ruta graveolens and structure-activity relationship studies against stored-food pests (Coleoptera). Journal of Food Protection, 78(8), 1536-1540.

Keane S \& Ryan MF (1999). Purification, characterization and inhibition by monoterpenes of acetylcholinesterase from the waxmoth, Galleria mellonella (L.). Insect Biochemistry and Molecular Biology, 29(12), 1097-1104.

Kennedy GG \& Dimock MB (1982). 2-Tridecanone: A natural toxicant in a wild tomato responsible for insect resistance. International IUPAC congress of pesticide chemistry, \& Takahashi N 1983. Pesticide chemistry. human welfare and the environment: proceedings of the 5th International Congress of Pesticide Chemistry, Kyoto, Japan, 29 August - 4 September 1982. Vol 2, 123-128.

Khani A \& Rahdari T (2012). Chemical composition and insecticidal activity of essential oil from Coriandrum sativum seeds against Tribolium confusum and Callosobruchus maculatus. ISRN Pharmaceutics 2012:1-5.

Kim SW, Lee HR, Jank MJ, Jung CS and Park IK (2016). Fumigant toxicity of lamiaceae plant essential oils and blends of their constituents against adult rice weevil Sitophilus oryzae. Molecules, 21, 361.

Kotsyukovsky M, Rafaeli A, Gileadi C, Demchenko N \& Shaaya E (2002). Activation of octopaminergic receptors by essential oil constituents isolated from aromatic plants: possible mode of action against insect pests. Pest Management Science, 58(11), 1101-1106.

Krishna-Ayyar PN (1930). A very destructive pest of stored products in south India Corcyra cephalonica (Stainton). Bulletin of Entomological Research, 25, 155-169.

Lin SYH, Trumble JT \& Kumamoto J (1987). Activity of volatile compounds in glandular trichomes of Lycopersicon species against two insect herbivores. Journal of Chemical Ecology, 13(4), 837-850.

Miresmailli S, Bradbury R \& Isman MB (2006). Comparative toxicity of Rosmarinus officinalis L. essential oil and blends of its major constituents against Tetranychus urticae Koch (Acari: Tetranychidae) on two different host plants. Pest Management Science, 62, 366-371.

Porel A, Sanyal Y \& Kundu A (2014). Simultaneous HPLC determination of 22 components of essential oils; Method robustness with experimental design. Indian Journal of Pharmaceutical Sciences, 76(1), 19-30.

Pumnuan J, Khurnpoon L \& Insung A (2015). Effects of insecticidal essential oil fumigations on physiological changes in cut Dendrobium Sonia orchid flower. Songklanakarin Journal of Science and Technology, 37(5), 523-531.

Rafeeq KUMA, Umadevi D, Sajitha N \& Gokuldas M (2016). Repellency of essential oil extracted from Cymbopogon citrates against the nuisance household pest, Luprops tristis Fab. (Coleoptera: Tenebrionidae). International Journal of Recent Scientific Research, 7(4), 10309-10313.

Rahuman AA \& Venkatesan P (2008). Mosquito larvicidal activity of oleic and linoleic acids isolated from Citullus colocynthis (Linn.). Schrad. Parasitol. Res 103:1383-1390.

Regnault-Roger C (1997). The potential of botanical essential oils for insect pest control. Integrated Pest Management Reviews, 2, 25-34. 
Robert R, Farrar Ir \& kennedy GG (1987). 2-Undecanone, a constituent of the glandular trichomes of Lycopersicon hirsutum f. glabratum: Effects on Heliothis zea and Manduca sexta growth and survival. Entomologia experimentalis et Applicata, 43(1),17-23.

Sode OJ, Mazaud F, \& Troude F (ed) (1995). Economics of grain storage. Proceedings of the International Symposium on Stored-Grain Ecosystem. Marcel Dekker, Inc., New York, USA.

Soleimani M, Aberoomand AP, Saber-Tehrani M \& Rustaiyan A (2009). Volatile composition of Ruta graveolens L of north of Iran. World Applied Science Journal, 7, 124-126.

Tripathi AK, Prajapati V, Khanuja SP \& Kumar S (2003). Effect of d-limonene on three three stored-product beetles. Journal of Economic Entomology, 96(3), 990-995.

Wekesa I, Onek LA, Deng AL, Hasanali A \& Othira JO (2011). Toxicity and repellent potency of Hyptis spicigera extracts on Sitophilus zeamais motschulsky (Coleoptera: Curculionidae). Journal of Stored Products and Postharvest Research, 2(6), 113-119.

Zhu L, Li Y, Li B, Lu B and Xia N (1993). Aromatic plants and essential constituents. Hai Feng Publishing, Hong Kong, pp 156.

Zhu, S., Lu, X., Dong, L, Xing, J, Su X, Kong H, Xu, G., \& Wu, C. (2005). Quantitative determination of compounds in tobacco essential oils by comprehensive two-dimensional gas chromatography coupled to timeof -flight mass spectrometry. Journal of Chromatography A, 1086, 107-114.

\section{Copyrights}

Copyright for this article is retained by the author(s), with first publication rights granted to the journal.

This is an open-access article distributed under the terms and conditions of the Creative Commons Attribution license (http://creativecommons.org/licenses/by/4.0/). 